\section{Utilização de marcadores de DNA para o diagnóstico genômico de animais domésticos: 2 . Deteç̧ão da mutação pontual causadora da Paralisia Hipercalêmica Periódica (HYPP) em eqüinos da raça Quarto de Milha}

\author{
Use of DNA markers for genomic diagnosis of domestic \\ animals: 2. Detection of point mutation causing Hyperkalemic \\ Periodic Paralysis (HYPP) in Quarter horses
}

\author{
José Fernando GARCIA'; André Sanches do Amaral GURGEL '; José Antonio VISINTIN²; \\ Vagner Ricardo LUNGE²; Marcelo Barbante DUARTE; ; Jarbas Leonel BERTOLLI ${ }^{4}$
}

CORRESPONDENCE TO

José Fernando Garcia

Departamento de Reprodução Anima

Facuidade de Medicina Veterinária e Zootecnia da USP

Av. Prof. Dr. Orlando Marques de

Paiva, 87 - Cidade Universitária

Armando de Salles Oliveira

05508-900 - São Paulo - SP - Brasil

e-mail: jfgarcia@usp.br

Faculdade de Medicina Veterinária e Zootecnia da USP - SP 2 - Centro de Biotecnologia do Estado do Rio Grande do Sul da UFRGS - RS

3 - Rancho's Tânia - Uberaba - MG

4 - Associação Brasileira dos

Criadores de Cavalo Quarto de Milha - São Paulo - SP

\title{
RESUMO
}

Analisaram-se 12 eqüinos da raça Quarto de Milha, descendentes da linhagem Impressive. Submeteram-se os DNAs, purificados a partir de leucócitos destes animais, à técnica de Polymerase Chain Reaction (PCR) e posterior digestão com a enzima de restrição Taq I. Estabeleceu-se, dessa maneira, o diagnóstico genômico da Paralisia Hipercalêmica Periódica (HYPP). Os exames revelaram que 9 animais eram portadores heterozigotos $(\mathrm{N} / \mathrm{H})$ e 3 , normais homozigotos (N/N). A partir do desenvolvimento da metodologia de PCR tornou-se possível diagnosticar o problema e propor maneiras de controle do alastramento desse gene defectivo na população por meio da detecção de animais portadores e normais.

UNITERMOS: Cavalos; Equidae; DNA; Paralisia; Hipercalemia.

\section{INTRODUÇÃO}

A Paralisia Hipercalêmica Periódica (HYPP) é uma doença muscular causada por um defeito genético hereditário que afeta o balanço de sódio e potássio das células musculares, podendo afetar tanto equiinos quanto humanos. A HYPP foi descrita primeiramente nos anos 50 em um agrupamento familiar humano, no qual foi reconhecida uma herança autossomal dominante (Gamstorp33; 1956). Uma síndrome de debilidade muscular em cavalos acompanhada de elevada concentração de potássio sérico, e que tinha bastante semelhança com uma doença hereditária humana, HYPP, foi descrita por Cox' (1985) e Steiss; Naylor'2 (1986). A hereditariedade em eqüinos foi conjecturada desde que a doença foi identificada pela primeira vez nesta espécie, mas a linhagem sangǘnea suspeita era muito popular e valiosa, levando à atuação cautelosa da comunidade veterinária na identificação da doença como herança específica e na citação da linhagem sangüínea envolvida. Desde então o conhecimento sobre esta doença tem aumentado drasticamente, tanto em humanos quanto em eqüinos. A possibilidade de uma herança autossomal dominante na HYPP equiina foi sugerida por Naylor et al. ${ }^{5}$ (1992), e, na convenção de 1992 da Associação Americana dos Criadores de Eqüinos, Spier et al.11. 12 (1990) apresentaram publicamente a linhagem sangüínea na qual foi localizado o gene defeituoso.

Esse defeito genético altera a abertura e fechamento dos canais de sódio das células musculares, dirigindo de maneira irregular o fluxo de sódio para dentro e o de potássio para fora das células. Essas alterações no fluxo de sódio e potássio mudam a corrente elétrica das células causando tremores incontrolados ou profunda debilidade muscular (Naylor et al.4, 1993). Altos níveis de potássio na corrente sanguínea podem estar associados com o aparecimento da paralisia. Equiinos com HYPP podem apresentar paralisias repentinas que, em casos graves, podem levar ao colapso e morte súbita decorrente de parada cardíaca e/ou insuficiência respiratória (Steiss; Naylor $\left.{ }^{12}, 1986\right)$. Os sinais clínicos de HYPP podem variar amplamente nos diferentes animais, e os eqüinos homozigotos são afetados mais gravemente do que os heterozigotos. Em condições ideais de manejo, o gene defectivo não manifesta efeitos adversos, mas o estresse e/ou o aumento de potássio sérico podem iniciar sinais clínicos de disfunção muscular (Duarte², 1993). Pode ser realizado tratamento clínico eficaz que varia desde o exercício leve do animal, que auxilia no retorno do potássio para dentro das células até a utilização de acetazolamida, que age como suave diurético, auxiliando na eliminação do 
GARCIA, J.F; GURGEI, A.S.A.; VISINTIN, J.A.; LUNGE, V.R.; DUARTE, M.B.; BERTOLLI, J.L. Utilização de marcadores de DNA para o diagnóstico genômico de animais domésticos: 2. Deteç̧ão da mutação pontual causadora da Paralisia Hipercalêmica Periódica (HYPP) em eqüinos da raça Quarto de Milha. Braz. J. vet. Res. anim. Sei. São Paulo, v.33, n. 3, p.1.36-138. 1996.

potássio pela excreção urinária (Naylor et al.6, 1992).

A alteração genética que causa HYPP foi resultado de uma mutação natural, transmitida por um gene autossômico dominante, não ligado ao sexo, com igual frequiência e não se diluindo de geração em geração. Os animais que possuem o gene defeituoso podem ser heterozigotos $(\mathrm{N} / \mathrm{H}$, apenas um alelo afetado) ou homozigotos $(\mathrm{H} / \mathrm{H}$, os dois alelos estão afetados).

HYPP está associada a equiinos com musculatura bem desenvolvida, não significando, entretanto, que a musculatura bem desenvolvida relacione-se com a doença. $O$ gene mutante causador de HYPP tem sido identificado nos descendentes do garanhão Impressive, tanto na raça Quarto de Milha quanto nas raças Appaloosa e American Paint Horse. Teoricamente é possível que outras mutações causem HYPP em diferentes linhagens, entretanto estas são mais difíceis de ser identificadas, porque não estão tão disseminadas.

A presença da mutação genética foi associada à doença em mais de 600 animais examinados nos Estados Unidos até janeiro de 1993 (Spier et al. ${ }^{10}, 1993$ ). Entretanto, 4 destes animais apresentaram sinais clínicos variáveis da doença muscular, mas os resultados para a mutação do gene da subunidade a da proteína do canal de sódio foram negativos (falsos negativos) (Spier et al. ${ }^{10}, 1993$ ). Porém existem evidências clínicas de que estes animais provavelmente apresentavam outra doença muscular, e não HYPP. Não houve a identificação de animais portadores da mutação genética que não tinham a doença (falsos positivos).

Com o aprimoramento de técnicas de biologia molecular, a identificação dos animais portadores é possível através da amplificação exponencial de um fragmento de DNA da região do gene da proteína do canal de sódio, pela técnica de PCR (Polymerase Chain Reaction) (Rudolph et al. ${ }^{8}, 1992$ ). Posteriormente esses fragmentos são submetidos ao tratamento com enzimas de restrição, capazes de clivar especificamente o fragmento de DNA no ponto onde ocorre a mutação. A eletroforese desses fragmentos de DNA em gel de poliacrilamida permite a identificação dos animais heterozigotos e homozigotos, sendo possível eliminar o problema por meio do cruzamento direcionado com animais negativos.

O objetivo deste trabalho foi identificar equiinos brasileiros da raça Quarto de Milha portadores de HYPP, por meio da técnica de PCR, previamente descrita por Rudolph et al. ${ }^{8}$ (1992).

\section{MATERIAL E MÉTODO}

DNAs genômicos foram purificados de amostras de sangue colhidas com EDTA, de 12 eqüinos da raça Quarto de Milha, descendentes da linhagem Impressive, utilizando protocolo clássico de fenol-clorofórmio (Sambrook et al.9, 1989). Os DNAs foram submetidos à técnica de Polymerase Chain Reaction (PCR) nas seguintes condições: 200 ng de DNA; 100 ng de cada oligonucleotídeo específico para a região do gene onde ocorre a mutação (5' GGGGAGTGTGTGCTCAAGATG 3' e 5' AATGGACAGGATGACAACCAC 3') (Rudolph et al. ${ }^{7}$, 1992); Taq Polimerase - 2 unidades; dNTPs 1,25 mM de cada nucleotídeo; tampão apropriado para a enzima; volume final $50 \mu \mathrm{l}$; coberto com 2 gotas de óleo mineral. Foram realizados 30 ciclos de amplificação $\left(94^{\circ} \mathrm{C}, 1\right.$ min.; $65^{\circ} \mathrm{C}, 4$ min.). Após esta etapa, alíquotas de $20 \mu \mathrm{l}$ das reações de amplificação foram digeridas com 1 unidade da enzima de restrição Taq I (incubação por 1 hora a $62^{\circ} \mathrm{C}$ ) e submetidas a eletroforese em gel de poliacrilamida $20 \%$ em tampão TBE. O gel foi corado com brometo de etídeo $(0,5 \mu \mathrm{g} / \mathrm{ml})$ e os fragmentos de DNA visualizados em transiluminador ultravioleta.

\section{RESULTADOS}

Foram analisados 12 animais dos quais 9 eram portadores $(\mathrm{N} / \mathrm{H})$ e 3 normais (N/N). A amplificação do DNA de todos os animais gerou um fragmento de 92 pares de bases que, após a digestão com a enzima Taq I, apresentou 3 fragmentos nos animais portadores $(\mathrm{N} / \mathrm{H})(92 \mathrm{pb}, 64 \mathrm{pb}$ e $28 \mathrm{pb})$ e 2 fragmentos nos normais $(\mathrm{N} / \mathrm{N})(64 \mathrm{pb}$ e $28 \mathrm{pb})$. A Fig. 1 mostra o resultado das amplificações por PCR de 3 animais, nas séries $A$ e $B$ animais $\mathrm{N} / \mathrm{H}$ e, na série $C$, animal $N / N$. $O$ fragmento de 28 pb não pode ser visualizado na eletroforese.

\section{DISCUSSÃO}

A adaptação da técnica de PCR para o diagnóstico da HYPP permite selecionar os animais negativos para a reprodução, auxiliando a eliminação do gene deletério da população equiina dentro das próximas gerações. Por ser o HYPP uma doença de caráter dominante, ao acasalar-se animais

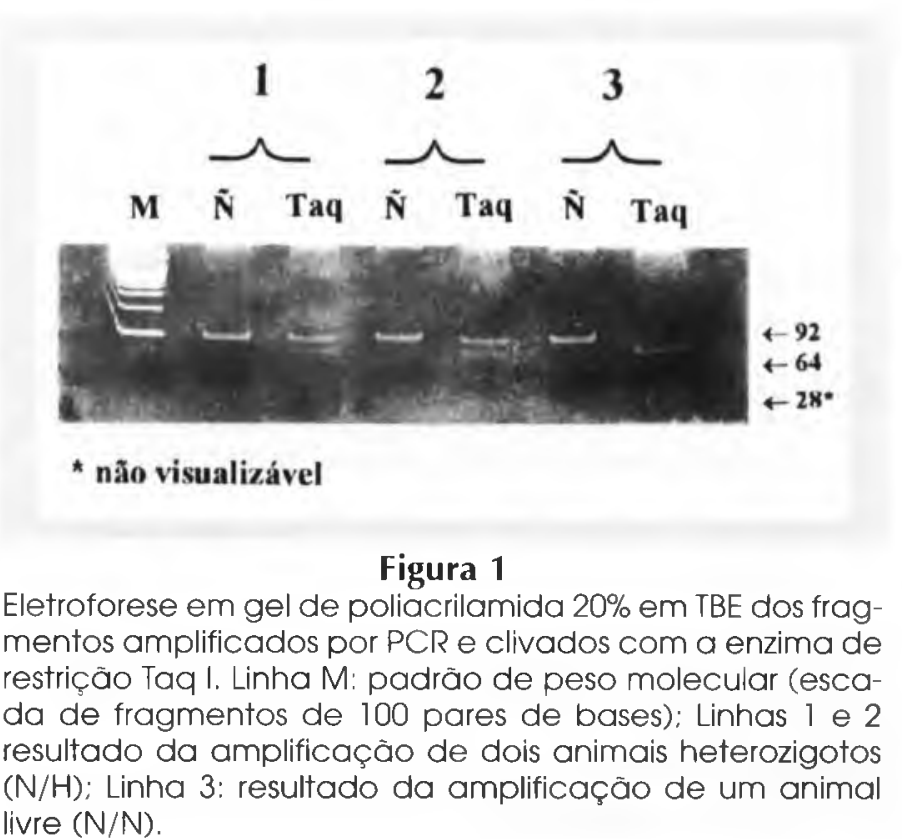




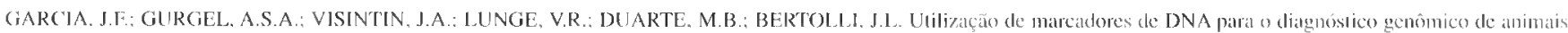

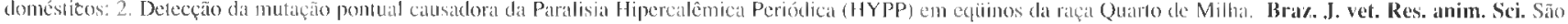
Paulo, v.33, n..3, p.136-1.38, 1996.

portadores $(\mathrm{N} / \mathrm{H})$ com animais livres da doença $(\mathrm{N} / \mathrm{N})$, obterse-á $50 \%$ de animais portadores, porém a avaliação desses animais e a utilização desses resultados como critério para a seleção de reprodutores deve ser observada. Apesar de outros fatores estarem envolvidos nos critérios de seleção dos reprodutores (alto valor de determinados animais e importância afetiva do cavalo para o homem), o acasalamento dirigido de animais previamente avaliados pode levar à redução drástica do aparecimento desse gene na população. Espera-se que com o controle correto, o número de portadores seja desprezível dentro de algumas gerações, sendo tendência a utilização somente de animais negativos. Além disso, o controle da gestação através do monitoramento ultrassonográfico, com a coleta do líquido amniótico para o teste precoce de HYPP, parece ser uma das soluções para a prevenção dessá doença.

\section{SUMMARY}

Twelve Quarter horses, descendants from Impressive line, have been analyzed. DNAs, purified from leukocytes of those animals, were submitted to Polymerase Chain Reaction technique (PCR) and digested by Taq I restriction enzyme. Accordingly the Hyperkalemic Periodic Paralysis (HYPP) genomic diagnosis was established. The tests revealed that 9 animals were carrier heterozygotes $(\mathrm{N} / \mathrm{H})$ and 3 normal homozygotes $(\mathrm{N} / \mathrm{N})$. Since the development of PCR methodology, it has been possible to diagnose the problem and plan ways to control the spreading of this defective gene in the population, through detection of carrier and normal animals.

UNITERMS: Paralysis; Hyperkalemia; Horses; Equidae; DNA.

\section{REFERÊNCIAS BIBLIOGRÁFICAS}

I-COX, J.H. An episodic weakness in four horses associated with intermittent serum hyperkalemia and the similarity of the disease to hyperkalemic periodic paralysis in man. In: ANNUAL CONVENTION OF THE AMERICAN ASSOCIATION OF EQUINE PRACTITIONERS, v.31. p.383-90, 1985. Proceedings.

2-DUARTE. M.B. Como conhecer e controlar a paralisia hipercalémica periodica (HYPP). Quarto de Milha, v.91, p.12-4, 1993.

3-GAMSTORP, 1. Adynamia episodica hereditaria. Acta Paediatrica Scandinavica, p.I-126, 1956 (Suplemento).

4-NAYLOR, J.M.: JONES, V.; BERRY, S.L. Clinical syndrome and diagnosis of hyperkalemic periodic paralysis in Quatrter horses. Equine Veterinary Journal, v.25, n.3, p.227-32, 1993.

5-NAYLOR, J.M.: ROBINSON, J.A : BERTONE, J. Familial incidence of hyperkalemic periodic paralysis in Quarter horses. Journal of the American Veterinary Medical Association. v.200, n.3. p. 340-3, 1992

6-NAYLOR, J.M.: ROBINSON. J.A: CRICHLOW, E.C.; STEISS. J.E. Inherilanee of myotonic discharges in American Quarter horses and the relationship to hyperkalemic periodic paralysis. Canadian Journal of Veterinary Research, v.56, n. I, p.62-6, 1992.

7-RUDOLPH, J.A.; SPIER, S.J.; BYRNS, G.; HOFFMAN, E.P. Linkage of hyperkalemic periodic paralysis in Quarter horses to the horse adult skeletal muscle sodium channel gene. Animal Genetic, v.23, n.3, p.24l-50, 1992

8-RUDOLPH, J.A.; SPIER, S.J.; BYRNS, G.: ROJAS. C.V: BERNOCO. D.: HOFFMAN, E.P. Periodic paralysis in Quarter horses: a sodium channel mutation disseminated by selective breeding. Nature Genetics, v.2, n.2, p.144-7, 1992.

9-SAMBROOK, J.; FRITSCH, E.F: MANIATIS, T. Molecular cloning: a laboratory manual. 2.ed. New York, Cold Spring, Harbor Laboratory Press, 1980

10-SPIER, S.J.: CARLSON, G.P.: HARROLD. D.: BOWLING, A.: BYRNS, G.; BERNOCO, D. Genetic study of hyperkalemic periodic paralysis in horses. Journal of the American Veterinary Medical Association. v.202, 1.6. p.933-7, 1993.

I I-SPIER, S.J.; CARLSON, G.P.; HOLLIDAY, T.A.; CARDINET, G.H.; PICKAR, J.G. Hyperkalemic periodic paralysis in horses. Journal of the American Veterinary Medical Association, v. 197, 11.8, p. 1009-17. 1990.
12-SPIER. S.J.: CARLSON. G.P.: PICKAR. J.: SNYDER, J.R.: HOLLIDAY. T.A.; CARDINET, G.H. Hyperkalemic periodic paralysis in horses: genetic and electrophysiologic studies. In: ANNUAL CONVENTION OF THE AMERICAN ASSOCIATION OF EQUINE PRACTITIONERS. v.35, P.399-402, 1990. Proceedlings

13-STEISS. J.E.; NAYLOR. J.M. Episodic muscle tremors in a Quarter horse: resemblance to hyperkalemic periodic paralysis. ('anadian Veterinary Journal, v.27, n. 9, p.332-5, 1986

Recebido para publicação: 30/09/94 Aprovado para publicação: $18 / 09 / 95$ 